\title{
Trauma-exposed Infants and Toddlers: A Review of Impacts and Evidence- Based Interventions
}

\author{
Alysse Melville
}

\begin{abstract}
Infants and toddlers are exposed to abuse and neglect at disproportionate rates compared to other children, setting a trajectory for disrupted developmental processes and increased vulnerability to future traumatic exposure. Social workers encounter traumaexposed young children across a number of systems, including but not limited to early childcare, family physical and mental health, court, and child welfare. It benefits social workers to have a working understanding of current research related to the bio-psychosocial impact of trauma on infants and young children and an awareness of current, research-driven interventions that can support young, at-risk children and families. This article reviews trauma-impacted development throughout the first two years of life with a discussion of current research exploring attachment and brain development and then discusses caregiver-child based interventions that work to repair disrupted attachment patterns, repair impaired regulatory processes, and return the caregiver-child relationship to a healthy developmental path.
\end{abstract}

Keywords: Trauma; infant mental health; early childhood; attachment; development; intervention

Current national estimates suggest that children from birth to age two years old make up over a quarter of substantiated cases of child maltreatment and almost three-quarters of abuse and neglect-related fatalities (U.S. Department of Health and Human Services, Administration for Children and Families, Administration on Children, Youth, and Families, \& Children's Bureau, 2015). The historical assumption of the natural resilience of very young children has been challenged by research showing trauma symptoms developing in children as early as three months of age (Cordón, Pipe, Sayfan, Melinder \& Goodman, 2004) and neuroendocrine responses to maternal trauma transmitted in utero (Yehuda et al., 2005). Despite the high prevalence rates of trauma exposure in children ages zero to two years, there is a dearth of available resources and interventions to address and mitigate trauma for infants and toddlers, especially targeted at social workers. This deficiency is evidenced by only seven out of 43 Empirically Supported Treatments and Promising Practices listed by the National Child Traumatic Stress Network as appropriate for children ages zero and up, and of those, only two specifically and exclusively address early childhood trauma (Child Parent Psychotherapy and Attachment and Biobehavioral Catch-up, both reviewed below). Social workers will no doubt encounter trauma-exposed infants and toddlers in their area of work, whether directly or through caregivers, and must be equipped to advocate for these at-risk children. This article explores the impact of trauma-exposure on children ages zero to two years, due to the disproportionately high rates of maltreatment exposure in this age range, with particular emphasis on the impact of trauma on attachment patterns, and a review of two promising evidence-backed interventions that are developmentally appropriate for infants and toddlers.

Alysse W. Melville, LCSW, is a doctoral student, School of Social Work, University of Connecticut, Hartford, CT. 


\section{Early Childhood Trauma}

Numerous types of trauma can impact infants and toddlers; these range from single, isolated traumatic events, such as natural disasters or car accidents, to chronic maltreatment and victimization, including domestic violence, neglect, physical abuse and sexual abuse. A traumatic event may be defined as an event that is overwhelming to the child's senses or self-regulatory abilities, threatens the child's well-being or that of their caregiver, indicates the world is uncontrollable and unpredictable, and/or involves stressors that exceed the child (or caregiver's) normal resources (Cordón, et al., 2004; Van Horn \& Lieberman, 2008). Chronicity of trauma (Streeck-Fischer \& Van der Kolk, 2000), the child's pretrauma adjustment (Feldman \& Vengrober, 2011), and the caregiver's reaction to the trauma (DeVoe, Klein, Bannon, \& Miranda-Julian, 2011) have all been linked to the severity of children's post-trauma functioning.

Impact of adversity. A number of domains are impacted by early maltreatment, including cognitive, behavioral, socio-emotional, and health. Compared to older children who have been maltreated, trauma-exposed children ages zero to two years are at greater risk for developing internalizing symptoms (Kaplow \& Widom, 2007) and have difficulties with inhibitory control and working memory (Cicchetti, Cowell, Rogosch, \& Toth, 2015). In addition, children who experience early adversity, such as abuse and neglect, are at greater risk than their non-maltreated peers for impaired executive functioning (DePrince, Weinzierl, \& Combs, 2009), a set of skills that predicts kindergarten school readiness (Fitzpatrick, McKinnon, Blair, \& Willoughby, 2014) as well as adult academic and job outcomes (Miller, Nevado-Montenegro, \& Hinshaw, 2012). Large-scale epidemiological studies such as the Adverse Childhood Experiences (ACE) study have analyzed the prevalence and effects of early childhood traumatic experiences in over 17,000 adults and have found relationships between early adverse childhood experiences and the prevalence of a number of adverse adult physical health outcomes (Dong, Anda, Dube, Giles, \& Felitti, 2003). Further, although not specific to children zero to two years old, children under 6 experience more ACEs than any other age (Thompson et al., 2015). Multiple ACEs in early childhood are associated with impaired social-emotional development (McKelvey, Whiteside-Mansell, Connors-Burrow, Swindle, \& Fitzgerald, 2016), increased risk of polyvictimization across childhood (Grasso, Ford, Dierkhising, Branson, \& Lee, 2015), belowaverage academic literacy skills and behavior problems (Jimenez, Wade, Lin, Morrow, \& Reichman, 2016), and increased rates of PTSD and internalizing symptoms in adulthood (Grasso et al., 2015). Taken together, these findings suggest that children zero to two years old are at risk of increased exposure to future experiences of trauma throughout childhood, as well as other potential negative developmental outcomes.

Diagnosis of early trauma. Critics of the DSM-IV's diagnosis of PTSD argued that it did not fit the complex symptoms that traumatized young children often present with (Feldman \& Vengrober, 2011) as it was dependent largely on the individual's ability to verbalize feelings, details, and expectations. In two studies that measured the impact of trauma on toddlers, none of the children in the study fit the formal DSM-IV criteria for PTSD (Mongillo, Briggs-Gowan, Ford, \& Carter, 2009). Similarly, among children in treatment for trauma with the National Child Traumatic Stress Network, fewer than a quarter met the criteria for PTSD. Other research found that assessment alternatives to the 
DSM-IV diagnosis (including changes ultimately adopted for use in DSM-5 [American Psychiatric Association (APA), 2013]) resulted in significantly more PTSD diagnoses in preschool-aged children, indicating that the DSM-IV may have underdiagnosed PTSD for a considerable number of preschool-aged children (Scheeringa, Myers, Putnam, \& Zeanah, 2012). Recent changes in the DSM-5 reflect the need for creating a developmentally appropriate diagnosis for traumatized children with the creation of a Preschool Subtype category for PTSD that helps to adapt the PTSD diagnosis to children under 6 years old (APA, 2013); however, these changes still do not reflect the specific impact of trauma on children ages zero to two years. In fact, although the DSM-5 notes that PTSD may occur at any age, it further clarified "beginning after the first year of life" (APA, 2013, p. 276). The limited assessment and diagnostic criteria addressing preverbal trauma, experienced by infants and toddlers, may limit insurance funding and federal Medicaid funding for early intervention services for this population.

\section{Development}

\section{Attachment}

The process of attachment is arguably most important in the earliest years, as it creates a biological framework for managing future stress and arousal (Streeck-Fischer \& Van der Kolk, 2000), thus shaping how a child interprets and reacts to future experiences. As infants are not able to decipher between distinct, different arousal states or verbalize their needs, they are dependent on caregivers to modulate their arousal and to care for their basic needs (Van der Kolk, 2006). During times of intense arousal or distress, secure children will return to behaviors that center on their primary attachment figure, such as seeking attention from or proximity to their caregiver; these behaviors elicit predictable caretaking responses in secure caregivers (Feldman \& Vengrober, 2011). As caregiver's moderate infant arousal by providing comfort and stimulation as well as by providing care for basic needs (such as changing a diaper or providing food), the infant learns the process of co-regulation (Ford, 2005). Secure and sensitive caregiving provides a type of safeguard against hyper-arousal and disorganization and infants begin to develop a sense of self and awareness of body cues, setting the stage for future development of self-regulation and affect tolerance (Feldman \& Vengrober, 2011).

The relationship between early childhood trauma and attachment can be seen from a number of angles; namely, whether the attachment figure perpetrated the trauma, whether the emotional needs of the child were met after the traumatic experience, and to what extent the parent was affected by the child's traumatic experience (Pynoos, Steinberg, \& Piacentini, 1999). The typical curiosity of the exploratory-orienting response that takes place as children begin to gain confidence in assessing and exploring the external world is also impacted by trauma, as children may instead choose to remain close to inconsistent or unpredictable caregivers. As children initially rely on their primary attachment figure's appraisal of contextual danger, a child with a neglectful or maltreating caregiver may be vulnerable to being without such early messages of danger and risk exploring too much. Conversely, the child may be exposed to a traumatized parent's over-estimation of danger, which may become internalized to the child (Pynoos et al., 1999). 
In circumstances where the caregiver is unable or unwilling to provide early arousal modulation and basic care to young children, the child is at risk of exposure to overwhelming levels and durations of arousal. This lack of regulation risks imprinting in a child's developmental processes that emotions and arousal in general are dangerous/frightening, leading to potential avoidance of arousal in the form of numbing/dissociation or a response in the other direction such as arousal in the form of aggressive behaviors (Streeck-Fischer \& Van der Kolk, 2000). In the Strange Situation, often used to observe and assess a toddler's response to separation from their primary caregiver, maltreated toddlers were found to be more likely to have disorganized attachments to caregivers (Cicchetti \& Toth, 1995) as well as higher levels of cortisol after parental separation (Twardosz \& Lutzker, 2010). Research with infants raised in countries engaged in war found that the mother's proximity to a traumatic event, not the child's proximity, was correlated with traumatic symptoms in children (Feldman \& Vengrober, 2011). Infants' and toddlers' evaluation of danger relies mainly on referencing their primary attachment figure, which leads to the potential for traumatization through their attachment figure (Pynoos et al., 1999). This may shed some light into the detrimental effects of witnessing domestic violence in the home.

\section{Neurobiological Development}

Early childhood development of attachment occurs within the context of fast-paced neural development, thus making it nearly impossible to separate the infant's growing primary attachment from the neurobiological systems that are developing around stress and affect regulation (Twardosz \& Lutzker, 2010; Van der Kolk, 2005). As experience shapes the brain through neural plasticity, synaptic connections that are use-dependent, either become strengthened or pruned based on early interactions with caregivers. The hypothalamic-pituitary-adrenal (HPA) axis is one such "use dependent" system which moderates arousal and regulation through a series of chemical reactions in the limbic system (Twardosz \& Lutzker, 2010). When an individual is stressed, cortisol is released through the adrenal gland as a result of the HPA-axis interactions, and stress responses such as increased heart rate, blood pressure, arousal and concentration are triggered (DeBellis, 2001; Twardosz \& Lutzker, 2010). In normal development, the stress response triggered by activation of the HPA axis and the release of cortisol through the adrenal gland is regulated by the hippocampus (Twardosz \& Lutzker, 2010). As the hippocampus triggers the stopping of the HPA-axis chemical interactions, the body is restored to homeostasis through decreased heart rate, blood pressure and arousal, thus allowing infants to flow in and out of states of arousal and regulation safely and with predictability. Predictable coregulation by the primary caregivers aids typical functioning and development of the HPA axis (Twardosz \& Lutzker, 2010).

Trauma-impacted development is also best understood through the intersection between neural development and social development, as it is difficult to address how trauma impacts attachment without a discussion of how attachment impacts the brain as well (Van der Kolk, 2005). Just as young children in responsive attachment relationships are able to organize their internal biological framework around expectations of safety and responsiveness from their caregivers (Streeck-Fischer \& Van der Kolk, 2000), early trauma can impact a child's organization by creating expectancies of the world as unsafe and 
unpredictable (Van der Kolk, 2005). The earlier discussed "use dependent" plasticity of the brain creates neural changes in children with chronic traumatic stress; creating a template of danger and survival through which later relationships and experiences are evaluated and processed (DeBellis, 2001; Pynoos et al., 2009). Primary trauma-related alterations in infant brain structure are in the HPA axis and the hippocampus (DeBellis, 2001; Ford, 2005). It is here that a major distinction between types of trauma becomes apparent; children with secure caregivers have a higher likelihood of developing a typical stress response system, as caregivers are able to continue to provide arousal modulation after a traumatic experience (Lieberman, 2004). However, if the trauma involves neglect or other maltreatment from the primary caregiver, chronic traumatic events, or traumatization of attachment figures (Feldman \& Vengrober, 2011), the HPA axis can become severely impacted (Pynoos et al., 1999). This may also be the case if trauma responses from the infant are so severe that they challenge the resources of otherwise secure and attuned attachment figures, who may be unable to regulate the child in the face of such trauma responses (Markese, 2011).

The activation of the HPA axis results in behaviors consistent with duress, such as anxiety, hyper-arousal, and hyper-vigilance (DeBellis, 2001). Chronic traumatic stress represents an over-activation of the HPA axis and a disruption to the hippocampal process of restoring homeostasis after duress, thus exposing children to abnormally long periods of hyper-aroused states (Ford, 2005). The "use-dependent" plasticity of the brain begins to organize neural connections by prioritizing skills relevant to survival, interfering with the strengthening of connections relevant to safe attachment systems (Pynoos, et al., 1999). The development of the pre-frontal cortex is shaped by early information that children receive from caregivers and the outside world, and is organized around early experiences, such as to expect stability/regulation, neglect/deprivation, or violence/fear (Twardosz \& Lutzker, 2010). As the prefrontal cortex aids children in interpreting information they receive from the outside world, a child who has been impacted by chronic traumatic stress may begin to build a cognitive framework where all information received from the outside world is interpreted as dangerous, thus perpetuating the cycle of persistent arousal (Twardosz \& Lutzker, 2010). Although there is much yet to be learned about the impact of early maltreatment on brain development, the amygdala and hippocampus have been implicated in work related to early trauma exposure. For example, exposure to prenatal, antenatal, and postnatal maternal anxiety was associated with infant hippocampal growth (Qiu et al., 2013). In addition, early trauma has been related to smaller brain volume, less connective matter, and neuronal losses in the corpus callosum and frontal cortex (DeBellis, 2001).

\section{Treatment Implications}

The complex and attachment-dependent nature of early childhood trauma emphasizes the need for therapeutic interventions that can include the caregiver-child relationship (Lojkasek, Cohen \& Muir, 1994). As discussed, trauma occurring within the developmental framework of early childhood has a direct impact on typical attachment processes, including trust formation and co-regulation which has an impact on the child's arousal modulation and agency/exploration (Pynoos et al., 2009; Van der Kolk, 2005). Important 
considerations for treatment include the intervention's ability to address and repair disrupted attachment processes by taking into consideration the primary caregivers present and past trauma and their experience of the child's trauma as well as whether the intervention is able to increase levels of mutual sensitivity (Lojkasek et al., 1994). Ford, Albert and Hawke (2008) suggest that interventions for early childhood trauma should emphasize increasing the ability of the child and the caregiver to consciously control and co-regulate their internal alarm system. It is important to note that not all attachment work needs to take place within the context of a biological parent-child relationship; other caregiving systems can include relatives, foster or adoptive parents, and residential staff (Arvidson et al., 2011; Ford, et al., 2008) and have been shown to similarly reduce cortisol levels and behavior problems in trauma-impacted youth (Twardosz \& Lutzker, 2010). Following are two evidence-backed interventions that effectively address risks associated with infant and toddler-exposure to trauma.

\section{Child-Parent Psychotherapy (CPP)}

Child-Parent Psychotherapy (CPP) is a relationship-based dyadic intervention for children from birth to age five who are experiencing difficulty as a result of traumatic events or relational disruptions (Lieberman \& Van Horn, 2011). CPP aims to address the young child's experience of trauma through the lens of the relationship, by increasing mutual sensitivity and responsiveness between the infant and the caregiver (Tucker, 2006), addressing the observable behavior of the infant (Jones, 2006; Lojkasek et al., 1994), and naming the unconscious processing that may be occurring as a result of the caregiver's prior attachment systems and experiences (Jones, 2006). The structure of the CPP model includes caregiver-child sessions that are structured to enable the parent and child to engage in free-play and spontaneous reactions to each other. These reactions may be explored in the moment by the clinician or reviewed during collateral sessions with the parent (Lieberman \& Van Horn, 2011). CPP supports the clinician's use of modeling, interpreting for the child as well as the provision of unstructured, reflective developmental guidance as a way to support the typical developmental trajectory of the child (Van Horn, Gray, Pettinelli, \& Estassi, 2012). CPP is able to simultaneously address the child and caregiver's experiences and reactions to trauma, while also restoring typical attachment patterns and the child's developmental trajectory. Maltreating families report higher rates of abuse and neglect in their own childhoods, as well as insecure attachment patterns with their own caregivers (Toth, Rogosch, Manly, \& Cicchetti, 2006). Because of the emphasis that CPP places on paying attention to the trauma of the caregiver's past and his or her ability to process the child's trauma, this dyadic form of therapy is also able to address the intergenerational transmission of trauma and attachment patterns from caregivers to their children (Van Horn \& Lieberman, 2008).

CPP has been more widely studied with trauma-exposed pre-school populations (Lieberman, Ghosh Ippen, \& Van Horn, 2006). Fewer studies have examined the impact of CPP with trauma-exposed children ages zero to two years. However, existing research with children ages zero to two years have found CPP to be linked to increased maternal empathy, and dyadic interaction, and decreases in infant's avoidance, resistance, and anger (Lieberman, Weston, \& Pawl, 1991) as well as increased rates of secure attachment, 
compared to maltreated infants who did not receive CPP (Toth et al., 2006). Children have been shown to be susceptible to trauma exposure in utero through caregiver exposure to interpersonal violence, stress, and trauma (Brand, Engel, Canfield, \& Yehuda, 2006). Perinatal CPP begins intervention with dyads during the mother's third trimester and continues until the child is 6 months of age. Perinatal CPP with chronic trauma and interpersonal violence exposed pregnant mothers has been linked to decreases in maternal depression and post-traumatic stress symptoms, as well as increases in child-rearing attitudes, particularly with mothers with initially low maternal-fetal attachment (Lavi, Gard, Hagan, Van Horn, \& Lieberman, 2015). CPP has been demonstrated to effectively address challenging early childhood behaviors related to trauma and attachment between caregivers and children, and has also been conceptualized as a developmentally appropriate intervention for pediatric medical trauma, such as invasive procedures or life-threatening illness (Bergeron, 2017).

Limitations of CPP center on the importance of the availability and engagement of a primary caregiver. If a caregiver is not willing or able to engage in CPP treatment then the fidelity to the model is compromised. CPP has been adapted to be used with young children who are placed out of the home, emphasizing the need for children to experience security even within complicated kinship or foster placements (Van Horn et al., 2012). CPP is a trauma-informed, developmentally-framed dyadic model that addresses the child's and caregiver's individual experiences while emphasizing that of the attachment relationship.

\section{Attachment and Biobehavioral Catch-up (ABC)}

Attachment and Biobehavioral Catch-up (ABC) is a 10 session, manualized, relational model that was developed to target the physiological and behavioral impacts of trauma in early childhood (Dozier, Bick \& Bernard, 2011; Dozier, Peloso, Lewis, Laurenceau, \& Levine, 2008). ABC uses the parent-child relationship to explore the impact of early trauma on the attachment relationship and to repair disruptions and distortions that occur as a result of altered stress-response systems and behavioral dysregulation in both children and their caregivers (Dozier et al., 2011). Throughout the 10 sessions, the clinician targets common trauma responses in attachment relationships, including the child pushing the parent away, the parent's own experiences that may interfere with attachment, such as past or current stressors, and the trauma-impacted child's adaptive physiological and behavioral responses (Dozier et al., 2008). ABC targets the behavioral and physiological dysregulation through play, during which time the clinician encourages and supports the parent in following the child's lead, responding to the child's cues, engaging with the child in regulating physical touch, and delighting in the child (Dozier et al., 2011). ABC addresses the parent experience through the use of videotaped parent-child interactions to show alternate attachment styles and emphasis on helping the parent become aware of automatic responses (Dozier et al., 2011).

In addition to caregiver sensitivity and maltreatment-related behaviors, studies of ABC have also explored outcomes related to the neurobiological underpinnings of attachment, trauma, and stress. A study comparing $\mathrm{ABC}$ to control interventions show significantly lower cortisol, a stress-hormone implicated in trauma and chronic stress exposure in children and adults, as well as fewer behavior problems post-intervention. In this study, 
children in the $\mathrm{ABC}$ intervention groups had levels of cortisol similar to children in the non-maltreated control group following treatment (Dozier et al., 2008). Differences in cortisol production between maltreated children who received the $\mathrm{ABC}$ intervention in infancy/toddlerhood were observed through longitudinal follow-up in preschool (Bernard, Hostinar, \& Dozier, 2015). Caregiver's event-related potentials (ERPs), a neurobiological marker of processing of their children's signals of emotion, and maternal sensitivity were enhanced in neglecting caregivers following the ABC intervention (Bernard, Simons, \& Dozier, 2015).

$\mathrm{ABC}$ has been studied across a number of settings, including with children in foster care, caregivers in inpatient treatment programs, and in community settings. A follow-up study of the use of $\mathrm{ABC}$ with children in foster care found that children who received the $\mathrm{ABC}$ intervention prior to age two had stronger cognitive flexibility than a control group (Lewis-Morrarty, Dozier, Bernard, Terracciano, \& Moore, 2012). In a study of the effects of the $\mathrm{ABC}$ intervention with mothers and infants in a residential substance-abuse treatment program, mean scores on observed sensitive parenting behavior measures were three times higher for the $\mathrm{ABC}$ intervention group than for the control group (Berlin, Shanahan, \& Carmody, 2014). Additionally, ABC has proven successful at improving parenting behaviors even when translated into community practice models of care (Caron, Weston-Lee, Haggerty, \& Dozier, 2016), demonstrating the ability to translate the ABC intervention successfully into social work agencies and community practice.

\section{Conclusion}

This article was written to provide an overview of the impact of trauma on the biopsychosocial development of children between birth and two years old, and as a guide for potential therapeutic interventions for this specific population. It does not cover all of the impacts of early childhood trauma, nor does it make a distinction between different types of trauma. It also does not provide a comprehensive or evidence-based review of the potential interventions, largely due to the minimal evidence-based research available for infant/toddler interventions.

Preverbal trauma must be assessed and addressed early, with developmentally appropriate interventions that target both the child and their primary attachment system and prevention models that focus on at-risk families and caregivers. Social workers encounter a number of at-risk, marginalized populations, including infants and toddlers. Social workers are poised as advocates for developmentally-sensitive, trauma-informed care and advocacy across a number of interdisciplinary settings. As more research uncovers the connection between early childhood experiences of trauma and adult mental and physical health problems (Dong et al., 2003), and more social workers engage in health care fields, more opportunities may arise to intervene with trauma-exposed young children in these and other interdisciplinary settings. Increased awareness and implementation of developmentally appropriate assessments, interventions, and policies to help traumaimpacted infants and toddlers may halt the cycle of trauma symptoms, restore healthy developmental trajectories, and promote well-being across the lifespan for future generations. 


\section{References}

American Psychiatric Association. (2013). Diagnostic and statistical manual of mental disorders (5th ed.). Arlington, VA: Author.

Arvidson, J., Kinniburgh, K., Howard, K., Spinazzola, J., Strothers, H., Evans, M., \& Blaustein, M. (2011). Treatment of complex trauma in young children:

Developmental and cultural considerations in application of the ARC intervention model. Journal of Child \& Adolescent Trauma, 4(1), 34-51. doi:

https://doi.org/10.1080/19361521.2011.545046

Bergeron, M. Y. (2017). Factors that support the use of child-parent psychotherapy as an intervention for child-parent dyads exposed to pediatric medical traumatic stress. Clinical Social Work Journal, 45(1), 77-87. doi: https://doi.org/10.1007/s10615-016$\underline{0585-2}$

Berlin, L. J., Shanahan, M., \& Carmody, K. A. (2014). Promoting supportive parenting in new mothers with substance-use problems: A pilot randomized trial of residential treatment plus an attachment-based parenting program. Infant Mental Health Journal, 35(1), 81-85. doi: https://doi.org/10.1002/imhj.21427

Bernard, K., Hostinar, C. E., \& Dozier, M. (2015). Intervention effects on diurnal cortisol rhythms of Child Protective Services-referred infants in early childhood: Preschool follow-up results of a randomized clinical trial. JAMA Pediatrics, 169(2), 112-119. doi: https://doi.org/10.1001/jamapediatrics.2014.2369

Bernard, K., Simons, R., \& Dozier, M. (2015). Effects of an attachment-based intervention on child protective services-referred mothers' event-related potentials to children's emotions. Child Development, 86(6), 1673-1684.

https://doi.org/10.11111/edev.12418

Brand, S. R., Engel, S. M., Canfield, R. L., \& Yehuda, R. (2006). The effect of maternal PTSD following in utero trauma exposure on behavior and temperament in the 9month-old infant. Annals of the New York Academy of Sciences, 107(1), 454-458. doi: https://doi.org/10.1196/annals.1364.041

Caron, E. B., Weston-Lee, P., Haggerty, D., \& Dozier, M. (2016). Community implementation outcomes of Attachment and Biobehavioral Catch-up. Child Abuse \& Neglect, 53, 128-137. doi: https://doi.org/10.1016/j.chiabu.2015.11.010

Cicchetti, D., Cowell, R., Rogosch, F., \& Toth, S. (2015). Childhood maltreatment and its effect on neurocognitive functioning: Timing and chronicity matter. Development and Psychopathology, 27(2), 521-533. doi: https://doi.org/10.1017/S0954579415000139

Cicchetti, D., \& Toth, S. L. (1995). A developmental psychopathology perspective on child abuse and neglect. Journal of the American Academy of Child \& Adolescent Psychiatry, 34(5), 541-565. doi: https://doi.org/10.1097/00004583-199505000-00008 
Cordón, I., Pipe, M., Sayfan, L., Melinder, A., \& Goodman, G. (2004). Memory for traumatic experiences in early childhood. Developmental Review, 24(1), 101-132. doi: https://doi.org/10.1016/j.dr.2003.09.003

DeBellis, M. D. (2001). Developmental traumatology: The psychobiological development of maltreated children and its implications for research, treatment, and policy. Development and Psychopathology, 13(3), 539-564. doi: https://doi.org/10.1017/S0954579401003078

DePrince, A. P., Weinzierl, K. M., \& Combs, M. D. (2009). Executive function performance and trauma exposure in a community sample of children. Child Abuse \& Neglect, 33(6), 353-361. doi: https://doi.org/10.1016/j.chiabu.2008.08.002

DeVoe, E. E., Klein, T., Bannon, W., \& Miranda-Julian, C. (2011). Young children in the aftermath of the World Trade Center attacks. Psychological Trauma: Theory, Research, Practice, and Policy, 3(1), 1-7. doi: https://doi.org/10.1037/a0020567

Dong, M., Anda, R. F., Dube, S. R., Giles, W. H., \& Felitti, V. J. (2003). The relationship of exposure to childhood sexual abuse to other forms of abuse, neglect, and household dysfunction during childhood. Child Abuse \& Neglect, 27(6), 625-639. doi: https://doi.org/10.1016/S0145-2134(03)00105-4

Dozier, M., Bick, J., \& Bernard, K., (2011). Attachment-based treatment for young, vulnerable children. In J. D. Osofsky (Ed.), Clinical work with traumatized young children (pp. 75-95). New York: Guilford Press.

Dozier, M., Peloso, E., Lewis, E., Laurenceau, J., \& Levine, S. (2008). Effects of an attachment-based intervention on the cortisol production of infants and toddlers in foster care. Development and Psychopathology, 20(3), 845-849. doi: https://doi.org/10.1017/S0954579408000400

Feldman, R., \& Vengrober, A. (2011). Posttraumatic stress disorder in infants and young children exposed to war-related trauma. Journal of the American Academy of Child \& Adolescent Psychiatry, 50(7), 645-658. doi: https://doi.org/10.1016/j.jaac.2011.03.001

Fitzpatrick, C., McKinnon, R., Blair, C., \& Willoughby, M. (2014). Do preschool executive function skills explain the school readiness gap between advantaged and disadvantaged children? Learning and Instruction, 30, 25-31. doi: https://doi.org/10.1016/j.learninstruc.2013.11.003

Ford, J. D. (2005). Treatment implications of altered affect regulation and information processing following child maltreatment. Psychiatric Annals, 35(5), 410-419.

Ford, J. D., Albert, D., \& Hawke, J. (2008). Prevention and treatment interventions for traumatized children: Restoring children's capacities for self-regulation. In D. Brom, R. Pat-Horenczyk, \& J. Ford (Eds.), Treating traumatized children: Risk, resilience and recovery (pp. 51-70). New York, NY: Routledge.

Grasso, D., Ford, J., Dierkhising, C., Branson, C., \& Lee, R. (2015). Developmental patterns of adverse childhood experiences and current symptoms and impairment in 
youth referred for trauma-specific services. Journal of Abnormal Child Psychology, 44(5), 1-16. doi: https://doi.org/10.1007/s10802-015-0086-8

Jimenez, M., Wade, R., Lin, Y., Morrow, L., \& Reichman, N. (2016). Adverse experiences in early childhood and adult health outcomes. Pediatrics, 137(2), 1-9. doi: https://doi.org/10.1542/peds.2015-1839

Jones, A. (2006). Levels of change in parent-infant psychotherapy. Journal of Child Psychotherapy, 32(3), 295-311. doi: https://doi.org/10.1080/00754170600996820

Kaplow, J. \& Widom, C. (2007). Age of onset of child maltreatment predicts long-term mental health outcomes. Journal of Abnormal Psychology, 116(1), 176-187. doi: https://doi.org/10.1037/0021-843X.116.1.176

Lavi, I., Gard, A. M., Hagan, M., Van Horn, P., \& Lieberman, A. F. (2015). Child-parent psychotherapy examined in a perinatal sample: Depression, posttraumatic stress symptoms and child rearing-attitudes. Journal of Social and Clinical Psychology, 34(1), 64-82. doi: https://doi.org/10.1521/jscp.2015.34.1.64

Lewis-Morrarty, E., Dozier, M., Bernard, K., Terracciano, S. M., \& Moore, S. V. (2012). Cognitive flexibility and theory of mind outcomes among foster children: Preschool follow-up results of a randomized clinical trial. Journal of Adolescent Health, 51(2), 517-522. doi: https://doi.org/10.1016/j.jadohealth.2012.05.005

Lieberman, A. F. (2004). Traumatic stress and quality of attachment: Reality and internalization in disorders of infant mental health. Infant Mental Health Journal, 25(4), 336-351. doi: https://doi.org/10.1002/imhj.20009

Lieberman, A. F., Ghosh Ippen, C., \& Van Horn, P. (2006). Child-parent psychotherapy: 6-month follow-up of a randomized controlled trial. Journal of the American Academy of Child \& Adolescent Psychiatry, 45(8), 913-918. doi: https://doi.org/10.1097/01.chi.0000222784.03735.92

Lieberman, A. F., \& Van Horn, P. (2011). Psychotherapy with infants and young children: Repairing the effects of stress and trauma on early attachment. New York: Guilford Press.

Lieberman, A. F., Weston, D. R., \& Pawl, J. H. (1991). Preventive intervention and outcome with anxiously attached dyads. Child Development, 62(1), 199-209. doi: https://doi.org/10.2307/1130715

Lojkasek, M., Cohen, N. J., \& Muir, E. (1994). Where is the infant in infant intervention? A review of the literature on changing troubled mother-infant relationships. Psychotherapy Theory Research \& Practice, 31(1), 208-220. doi: http://dx.doi.org/10.1037/0033-3204.31.1.208

Markese, S. (2011). Dyadic trauma in infancy and early childhood: Review of the literature. Journal of Infant, Child, and Adolescent Psychotherapy, 10(2-3), 341378. https://doi.org/10.1080/15289168.2011.600214 
McKelvey, L. M., Whiteside-Mansell, L., Connors-Burrow, N. A., Swindle, T., \& Fitzgerald, S. (2016). Assessing adverse experiences from infancy through early childhood in home visiting programs. Child Abuse \& Neglect, 51, 295-302. doi: https://doi.org/10.1016/j.chiabu.2015.09.008

Miller, M., Nevado-Montenegro, A. J., \& Hinshaw, S. P. (2012). Childhood executive function continues to predict outcomes in young adult females with and without childhood-diagnosed ADHD. Journal of Abnormal Child Psychology, 40(5), 657668. doi: https://doi.org/10.1007/s10802-011-9599-y

Mongillo, E., Briggs-Gowan, M., Ford, J., \& Carter, A. (2009). Impact of traumatic life events in a community sample of toddlers. Journal of Abnormal Child Psychology, 37(4), 455-468. doi: https://doi.org/10.1007/s10802-008-9283-Z

Pynoos, R. S., Steinberg, A. M, Layne, C.M., Briggs, E. C., Ostrowski, S. A., \& Fairbank J. A. (2009). DSM-V PTSD diagnostic criteria for children and adolescents: A developmental perspective and recommendations. Journal of Trauma Stress, 26(1), 391-398. doi: https://doi.org/10.1002/jts.20450

Pynoos, R. S., Steinberg, A. M., \& Piacentini, J. C. (1999). A developmental psychopathology model of childhood traumatic stress and intersection with anxiety disorders. Biological Psychiatry, 46(11), 1542-1554. doi: https://doi.org/10.1016/S0006-3223(99)00262-0

Qiu, A., Rifkin-Graboi, A., Chen, H., Chong, Y-S., Kwek, K., ..Meaney, M. J. (2013). Maternal anxiety and infants' hippocampal development: Timing matters. Translational Psychiatry, 3(9), 1-7. doi: https://doi.org/10.1038/tp.2013.79

Scheeringa, M. S., Myers, L., Putnam, F. W., \& Zeanah, C. H. (2012). Diagnosing PTSD in early childhood: An empirical assessment of four approaches. Journal of Traumatic Stress, 25, 359-367. doi: https://doi.org/10.1002/jts.21723

Streeck-Fischer, A., \& Van der Kolk, B. (2000). Down will come baby, cradle and all: Diagnostic and therapeutic implications of chronic trauma on child development. Australian \& New Zealand Journal of Psychiatry, 34(6), 903-918. doi: https://doi.org/10.1080/000486700265

Thompson, R., Flaherty, E., English, D., Litrownik, A., Dubowitz, H., Kotch, J., \& Runyan, D. (2015). Trajectories of adverse childhood experiences and self-reported health at age 18. Academic Pediatrics, 15, 503-509. doi: https://doi.org/10.1016/j.acap.2014.09.010

Toth, S., Rogosch, F., Manly, J., \& Cicchetti, D. (2006). The efficacy of toddler-parent psychotherapy to reorganize attachment in the young offspring of mothers with major depressive disorder: A randomized preventive trial. Journal of Consulting and Clinical Psychology, 74(6), 1006-1016. doi: https://doi.org/10.1037/0022006X.74.6.1006 
Tucker, J. (2006). Using video to enhance the learning in a first attempt at 'Watch, Wait and Wonder'. Infant Observation, 9(2), 125-138. doi:

https://doi.org/10.1080/13698030600810359

Twardosz, S., \& Lutzker, J. (2010). Child maltreatment and the developing brain: A review of neuroscience perspectives. Aggression \& Violent Behavior, 15(1), 59-68. doi: https://doi.org/10.1016/j.avb.2009.08.003

U.S. Department of Health and Human Services, Administration for Children and Families, Administration on Children, Youth and Families, Children's Bureau. (2015). Child Maltreatment 2013. Available from http://www.acf.hhs.gov/programs/cb/research-data-technology/statisticsresearch/child-maltreatment

Van der Kolk, B. A. (2005). Developmental trauma disorder: Toward a rational diagnosis for children with complex trauma histories. Psychiatric Annals, 35(5), 401-408.

Van der Kolk, B. A. (2006). Clinical implications of neuroscience research in PTSD. Annals of the New York Academy of Sciences, 1071(1), 277-293. doi: https://doi.org/10.1196/annals.1364.022

Van Horn, P., Gray, L., Pettinelli, B., \& Estassi, N. (2012). Child-parent psychotherapy with traumatized young children in kinship care: Adaptation of an evidence-based intervention. In J. D. Osofsky (Ed.), Clinical work with traumatized young children (pp. 55-74). New York: Guilford Press.

Van Horn, P., \& Lieberman, A. (2008). Using dyadic therapies to treat traumatized young children. In D. Brom, R. Pat-Horenczyk, \& J. Ford (Eds.), Treating traumatized children: Risk, resilience, and recovery (pp. 51-70). New York: Routledge.

Yehuda, R., Mulherin Engel, S., Brand, S., Seckl, J., Marcus, S., \& Berkowitz, G. (2005). Transgenerational effects of posttraumatic stress disorder in babies of mothers exposed to the World Trade Center attacks during pregnancy. The Journal of Clinical Endocrinology \& Metabolism, 90(7), 4115-4118. doi: https://doi.org/10.1210/jc.2005-0550

Author note: Address correspondence to Alysse Melville, School of Social Work, University of Connecticut, 38 Prospect Street, Hartford, CT 06103, 203-313-9498, alysse.melville@uconn.edu 